\title{
Extradural application of bismuth iodoform paraffin paste causing relapsing bismuth encephalopathy: a case report with CT and MRI studies
}

\author{
Rewati Raman Sharma, Ian P Cast, Robert M Redfern, Cieran O'Brien
}

\begin{abstract}
Bismuth iodoform paraffin paste (BIPP) is used in dressings in ear, nose, and throat, dental, and neurosurgical practice. Neurotoxicity due to absorption of bismuth from the BIPP pack is rare. It is preventable and reversible but likely to be fatal if unrecognised. A case of relapsing but reversible toxic encephalopathy due to a large extradural BIPP pack is reported in a 57 year old Caucasian woman, operated on for a huge basal cell carcinoma of the vertex invading the skull and extradural space. Clinical, neuroradiological (CT and MRI), and biochemical studies are presented and discussed in the light of the available literature.
\end{abstract}

(F Neurol Neurosurg Psychiatry 1994;57:990-993)

Rutherford Morrison introduced BIPP in 1916. ${ }^{1}$ It contains two parts of iodoform and one part of bismuth subnitrate or carbonate in a liquid paraffin base. It has many applications particularly in oral, maxillofacial, ear, nose, and throat, and neurosurgical practices.

Its principle uses in neurosurgery are packing after trans-sphenoidal surgery, skull base surgery, and chronic infective scalp wounds. The use of BIPP makes impregnated gauze impervious to blood and body fluids ensuring little nutrition for bacteria to thrive in its interstices. ${ }^{2}$ It also has the ability to stimulate granulation tissue. Its stability in the presence of necrotic tissue resulting in clean manageable cavities is remarkable in our experience.

Reports of neurotoxicity after absorption of bismuth from a BIPP pack are infrequent. ${ }^{34}$ We report a case of relapsing encephalopathy after chronic extradural application of a large BIPP pack.

\section{Case report}

A 57 year old right handed housewife presented in March 1991 with a nine month history of a progressively enlarging huge subgaleal mass surmounted by a foul smelling ulcer overlying the posterior part of the vertex. Neuroradiological studies confirmed a large extracranial mass destroying the under- lying bone and involving the extradural space with displacement but not occlusion of the superior sagittal sinus.

A basal cell carcinoma (weight $675 \mathrm{gm}$ ) was removed en bloc on 3 May 1991. Large areas of dura mater were thus exposed bilaterally with the intervening sagittal sinus. All were packed with BIPP. Post operatively she received $5500 \mathrm{cGY}$ in 20 fractions over four weeks with $4 \mathrm{MeV} x$ rays.

In early July 1991 she gradually became progressively agitated and confused with intermittent bihemispheric signs. She eventually lapsed into a coma. There was no meaningful neurological response in the limbs for many weeks but she maintained her vital signs and self ventilation. CT of the brain showed diffuse cerebral oedema in both parieto-occipital lobes, more on the right side.

In December 1991 the BIPP pack was removed. She thereafter showed a progressive return to full alertness, rapport, cognition, and coordinated bodily activity.

On 20 December CT showed complete resolution of cerebral oedema but the appearance of patchy areas of high attenuation in the right parieto-occipital cortex subjacent to the exposed dura mater.

The "ulcer" remained unsuitable for grafting due to the presence of immature granulations, areas of slough, and a wide rim of blackened devitalised bone. A large BIPP pack was reapplied in the hope of obtaining a clean granular bed for later grafting. After this procedure she again became progressively restless, dysarthric, insomnolent, and confused. On 26 April 1992 she showed a relatively rapid deterioration in her conscious level and became unresponsive. The possibility of bismuth toxicity was considered and the BIPP pack was again removed. Blood bismuth concentration was $52 \mathrm{ng} / 1$ (April 1992). Her conscious level once more improved to normal over a fortnight with the blood bismuth concentration falling to $24 \mathrm{ng} / \mathrm{l}$ on 14 May 1992. The idea of bismuthism was more certain although she had never displayed typical myoclonic jerks as described with oral ingestion of bismuth salts on a long term basis.

Periodic CT showed abnormal features of extensive cerebral oedema and high attenuation in the parieto-occipital cerebral cortex (fig 1). On MRI (axial and coronal scans) the 
Figure 1 CT scan showing extensive white matter oedema causing a mass effect and high attenuation of the parietooccipital cerebral cortex (more on the right).

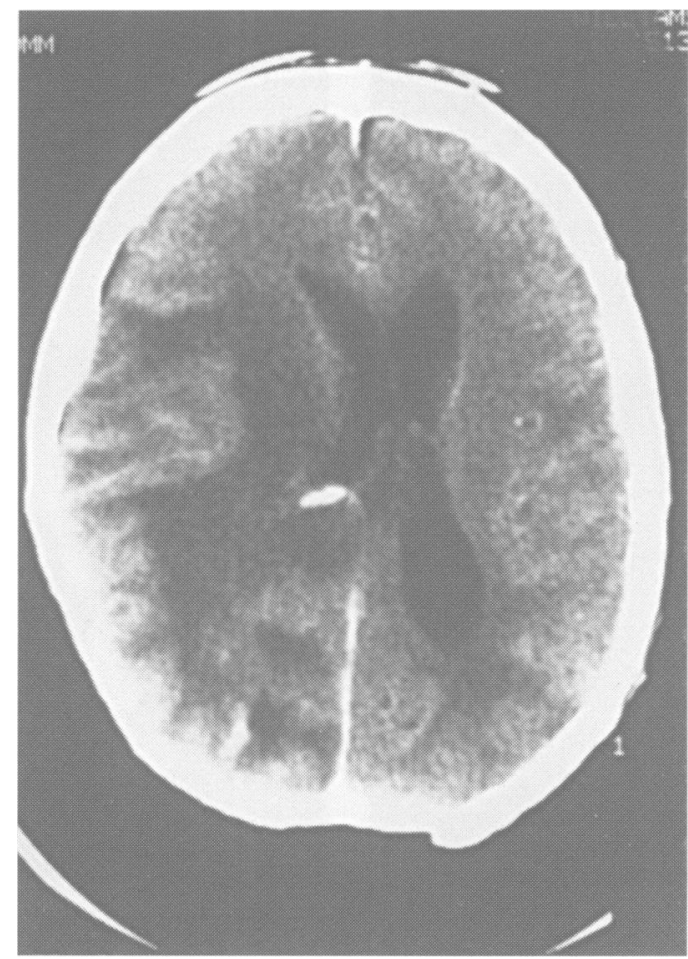

changes were more extensive both in $\mathrm{T} 1$ and T2 images (fig 2). Recent CT showed evidence of cerebral atrophy but no evidence of tumour. The naked dura is currently covered by a simple dressing of sofratulle and lyofoam. Her neurological state remains satisfactory.

\section{Discussion}

Fatal poisoning (accidental ingestion or parenteral injections) and mild toxicities such as dermatitis, skin rashes, and allergic reactions (local application) are well recognised but infrequent complications of bismuth treatment. ${ }^{5}$ Although brain damage by bismuth was recorded as early as 1922 by Levaditi, ${ }^{6}$ it has been refuted by some. ${ }^{7}$

In 1973,29 cases of bismuth neurotoxicity were reported in Australia. ${ }^{89}$ All recovered after discontinuing the drug. In France, 950 cases of bismuth encephalopathy were reported; 70 were fatal. ${ }^{8}$ In both series oral preparations of bismuth had been given for various bowel disorders. The neurological syndromes were characterised by increasing confusion, ataxia, and myoclonus.

Kruger et $a l^{5}$ suggested that bismuth binds with the thiol group of enzymes in cerebral intracellular enzyme systems concerned with oxidative cerebral metabolism. Bismuth crosses the blood-brain barrier and disturbs oxidative cerebral metabolism causing increased lactate production, decreased consumption of oxygen and glucose, and lowered cerebral blood flow.

Transient facial paralysis related to BIPP packing was reported in 1985 in a 58 year old Caucasian woman who had an infected mastoidectomy cavity and a benign aural polyp of the facial ridge. ${ }^{3}$ Another case of neurotoxicity (reversible bismuth encephalopathy) was reported in which a large BIPP pack was used after surgery for keratocyst of the mandible. Seven weeks later the patient presented with general malaise, insomnia, and mild Parkinsonian tremors with stiff arms. The blood bismuth concentration was greater than $30 \mathrm{ng} / \mathrm{l}$. He recovered completely after removal of the BIPP pack.

In the case now reported, two separate instances occurred where the manifestations of neurotoxicity were progressive agitated confusion, insomnia, dysarthria, and then deterioration in the level of consciousness leading to coma. The patient recovered spontaneously after removal of the BIPP pack on both occasions. Her clinical state correlated well with the blood bismuth concentrations during the second episode. Although the blood bismuth concentrations were not estimated during the first episode of toxic encephalopathy the relapsing and remitting course of the disease correlated so well with the BIPP application and discontinuation that a causal relation seems highly probable.

The normal concentration of bismuth in blood is between $1-5 \mathrm{ng} / 1 .^{410} \mathrm{~A}$ safety value of $30-50 \mathrm{ng} / \mathrm{l}$ and an alarm concentration of 100 ng/l have been suggested in the past but no proof is available to support the choice of these concentrations. ${ }^{10}$ According to Serfontein and Mekel, ${ }^{11}$ blood bismuth concentrations do not seem to reflect bismuth concentration in the brain. Blood bismuth may return to normal but high concentrations of intracerebral bismuth may still exist.

Escourolle et $a l^{12}$ have reported 12 postmortem studies of bismuth poisoning after oral ingestion. In these cases the concentration of bismuth in the brain tissue was more than $2 \mathrm{mg} / \mathrm{kg}, 100$ to 1000 times higher than in the normal brain. The concentration of bismuth is highest in the grey matter especially in the basal ganglia, cerebral cortex, and cerebellar cortex as well as in the meninges. Interestingly, in a fatal case of bismuth encephalopathy described by Liessens et $a l^{13}$ after oral ingestion of bismuth salt, the concentration of bismuth in visceral organs and different parts of the CNS remained very high despite a drastic decrease of blood bismuth. They found histopathological evidence of non-specific anoxic lesions including widespread loss of Purkinje cells in the cerebellum. The blood bismuth concentration of 52 $\mathrm{ng} / \mathrm{l}$ in our case where BIPP was applied locally over the dura mater was significant. There were no typical myoclonic seizures. These however, have only been reported in patients who had bismuth blood concentrations ranging from 150 to $2200 \mathrm{ng} / 1 .{ }^{14} 15$

Findings from CT showing diffuse low attenuation areas in the brain with patchy areas of increased attenuation in the basal ganglia and the cerebral cortex have been reported by Gardeur et $a l^{15}$ in five cases of bismuth encephalopathy after oral ingestion of bismuth salts. The increased attenuation in the grey matter contrasted with decreased 

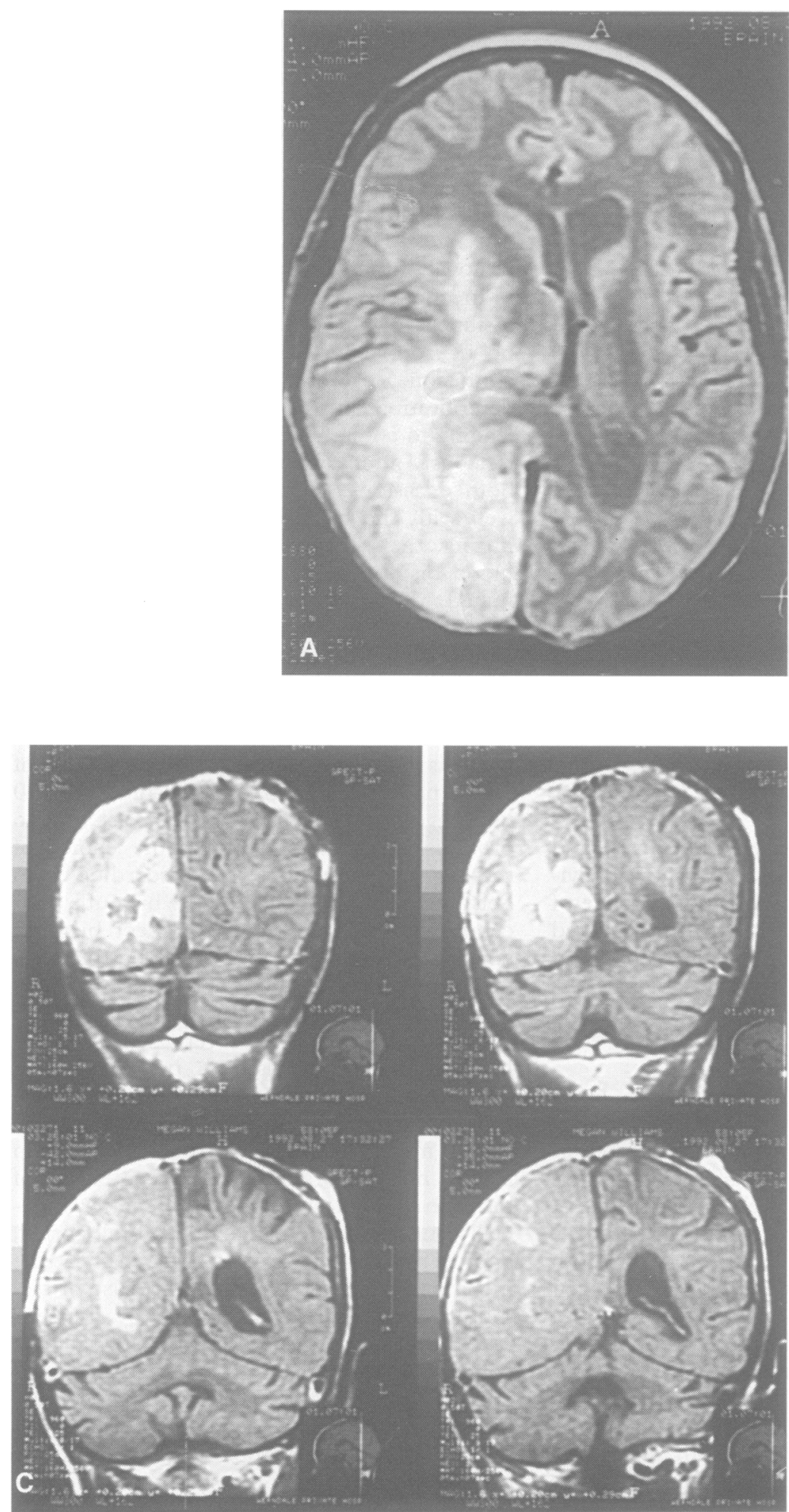

Figure 2 MRI (axial views: T1 $(A)$ and T2 (B) images) showing extensive cerebral oedema and hyperintense areas in the dura mater, central white matter (crumpled olive appearance), and periventricular ependymal lining, more clearly visible on sequential coronal scans $(C)$.

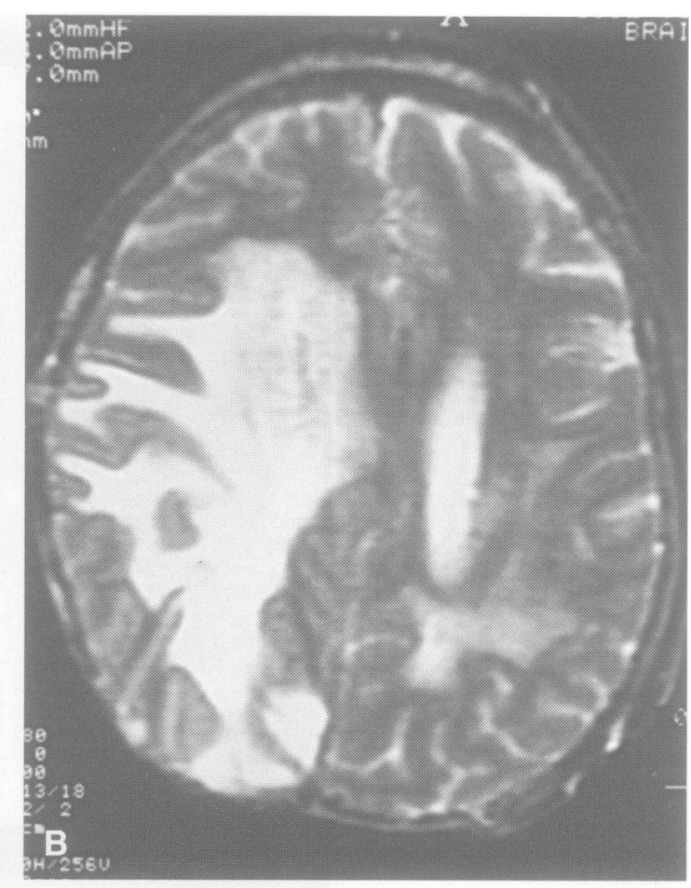

The areas of increased attenuation seen in the cerebral CT studies are most certainly related to the high intracellular bismuth concentration in the cerebral tissue. The high atomic number of bismuth $(Z=83)$ is responsible for the increased attenuation values. ${ }^{15}$ The CT findings in our case characterised by diffuse areas of low attenuation in both parieto-occipital regions subjacent to the BIPP pack were suggestive of cerebral oedema with mass effect and increased attenuation in the dura mater and subjacent cortex suggest local absorption of bismuth from the BIPP pack via the adjacent dura mater or its circulation. MRI showed far more extensive cerebral oedema and peculiar stippled and crumpled olive appearances in deep white matter.

Although the role of bismuth in antisepsis requires further clarification, there is clinical evidence that BIPP is efficacious in the management of postoperative surgical cavities. It alters the course of local recurrence of chronic infections in ear, nose, and throat, dental, and neurosurgical practices, and promotes granulations. Bismuth encephalopathy is a major concern, however, that needs to be considered, particularly if long term application is likely to lesions in close proximity to neural tissue.

\section{Conclusions}

Long term extradural application of a large BIPP pack may cause bismuth encephalopathy. Diffuse cerebral oedema subjacent to the BIPP pack and abnormal changes in the cerebral cortex, deep white matter, and deep nuclear masses may be seen on CT and MRI (more pronounced with MRI). Blood bismuth concentrations may be increased, correlating well with the clinical state. One such case is reported. 
Close attention to neurological and psychiatric symptoms is mandatory in anyone treated long term by BIPP packings, particularly in those cases where packs are immediately adjacent to neural tissue. Routine estimation of blood bismuth concentrations in patients so treated may be appropriate.

We gratefully thank Mrs Ann Langford for the preparation of this manuscript, and Dr E W Jones and Dr N Powell, neuroradiologists, for the $C T$ and $M R I$ studies. The patient was originally admitted under the care of $\mathrm{Mr}$ P J E Wilson, formerly consultant neurosurgeon at Morriston Hospital, Swansea. Blood bismuth concentrations were assayed by the MRC Heavy Metal Toxicity Unit, New Cross Hospital, London.

1 Morrison R. The treatment of infected suppurating war

wounds. Lancet 1916;ii:268-72.
2 Nigam A, Allwood MC. BIPP-How does it work? Clin Otolaryngol 1990;15:173-5.

3 Jones PH. BIPP allergy causing facial paralysis. 7 Laryngol Otol 1985;99:389-90.

4 Jones JAH. BIPP: A case of toxicity? Oral Surg Oral Med Oral Pathol 1990;69:668-71.

5 Kruger G, Thomas DJ, Weinhardt F, Hoyes. Disturbed oxidative metabolism in organic brain syndrome caused by bismuth in skin creams. Lancet 1976;ii:485-7. 6 Levaditi C. Presse Med 1922;59:633 (cited in Kruger et $\left.a P^{5}\right)$.

7 Belilies RP. In: Caserett LJ, Doull J. eds. Toxicology. New York: 1975:467 (cited in Kruger, et $a P$ )

8 Le Quesne PM. Toxic substances and the nervous system: the role of clinical observation. $f$ Neurol Neurosurg Psychiatry $1981 ; 44: 1-8$.

9 Le Quesne PM. Metal induced diseases of the nervous system. Br ₹ Hosp Med 1982;28:534-8.

10 Slikkerveer A, de Wolff FA. Pharmacokinetics and toxicity of bismuth compounds. Med Toxicol Adverse Drug Experience 1989;4:303-23.

11 Serfontein WJ, Mekel R. Bismuth toxicity in man. II Review of bismuth blood and urine levels in patients after administration of therapeutic bismuth formulations in relation to the problem of bismuth toxicity in man. Res Commun Chem Pathol Parmacol 1979;26:391-411.

12 Escourolle R, Bourdon R, Galli A, et al. Etude neuropathologique et toxicologique de douze cas d encephalopathie bismuthique. Rev Neurol (Paris) 1977;

Liessens JL, Monstrey J, Vanden Eeckhout E, Djudzman $\mathrm{R}$, Martin JJ. Bismuth encephalopathy. A clinical and anatomo-pathological report of one case. Acta Neurol Belg 1978;78:301-9.

14 Buge A, Suprino-Viterbo V, Rancurel G, Pontes C. Epileptic phenomena in bismuth toxic encephalopathy. f Neurol Neurosurg Psychiatry 1981;44:62-7.

15 Gardeur D, Buge A, Rancurel G, Dechy H, Metzger J. Bismuth encephalopathy and cerebral computed tomography. $\mathcal{F}$ Comp Assist Tomogr 1978;2:436-8. 